\title{
Designing a Multiaxial Extensometric Force Platform: A Manufacturing Experience
}

\author{
Jorge Rodolfo Beingolea ${ }^{1, * \mathbb{D}}$, Helder Andrade Rodrigues ${ }^{1}$, Milagros Zegarra ${ }^{2} \mathbb{D}$, Erasmo Sulla-Espinoza ${ }^{2} \mathbb{D}$, \\ Romildo Torres-Silva ${ }^{3}$ and Jorge Rendulich ${ }^{2}$ (D) \\ 1 Department of Electronic Systems Engineering, University of São Paulo, São Paulo 05508-010, Brazil; \\ helder.rodrigues@pad.lsi.usp.br \\ 2 Department of Electronic Engineering, Universidad Nacional de San Agustin de Arequipa, \\ Arequipa 04001, Peru; mzegarra@unsa.edu.pe (M.Z.); esullae@unsa.edu.pe (E.S.-E.); \\ jrendulich@unsa.edu.pe (J.R.) \\ 3 Núcleo de Pesquisas Tecnológicas, Universidade Mogi das Cruzes, Mogi das Cruzes 08780-911, Brazil; \\ rtorres_63@hotmail.com \\ * Correspondence: jorge.beingolea@alumni.usp.br; Tel.: +55-11-30919741
}

check for updates

Citation: Beingolea, J.R.; Rodrigues, H.A.; Zegarra, M.; Sulla-Espinoza, E.; Torres-Silva, R.; Rendulich, J.

Designing a Multiaxial Extensometric Force Platform: A Manufacturing Experience. Electronics 2021, 10, 1907. https://doi.org/10.3390/

electronics10161907

Academic Editor: Enzo

Pasquale Scilingo

Received: 16 June 2021

Accepted: 25 July 2021

Published: 9 August 2021

Publisher's Note: MDPI stays neutral with regard to jurisdictional claims in published maps and institutional affiliations.

Copyright: (c) 2021 by the authors. Licensee MDPI, Basel, Switzerland. This article is an open access article distributed under the terms and conditions of the Creative Commons Attribution (CC BY) license (https:/ / creativecommons.org/licenses/by/ $4.0 /)$.

\begin{abstract}
Studies that lead to the development of more accessible and low-cost electronic technologies and devices for biomechanical and biomedical analysis applications are becoming increasingly needed. In this work, the development of a multiaxial extensometric force platform will be addressed, aiming to improve the sensitivity and reduce the costs of existing platforms. Additionally, this platform can be used for analysis and characterization of flight time and postural characterization of volleyball athletes. As a result, a functional and easily produced prototype was created, due to the processes used (final cost of the developed platform-USD\$100). The interfaces of visualization and analysis of the device functions were designed in LabView. The purpose of the experiments is to perform flight analysis of athletes, and all functions designed for the platform strength and endurance are focused on that same purpose. The prototype's functions were evaluated by applying loads from 700 to $1000 \mathrm{~N}$ (Newtons) and its future integration with other instruments such as the surface electromyography (EMG) and an electrocardiogram (ECG) is expected to form an instrument kit that improves the characterization of studies of balance, strength and muscular endurance.
\end{abstract}

Keywords: force platforms; electronic devices; postural analysis; multiaxial extensometric; biomedical devices

\section{Introduction}

The demand for studies that promote the development of new electronic, biomechanical and other devices that will reduce the costs of analysis, treat postural problems and the degradation of muscle power in athletes and in the elderly population is increasing [1-3].

Applying several methods and techniques that include the use of force platforms for conducting postural analysis studies is not new. However, these studies are not focused on the improvement of force platforms, their precision and low cost, but only in their use as a product for sports professionals and physiotherapists.

As an example, some studies use force platforms to apply the method of ground reaction forces on each child's foot. Their objective is to apply a method that decomposes ground reaction forces (GRF) profiles, right and left, in relation to the GRF profile registered on the platform, to identify atypical postures [4]. In the study by P. Kutilek et al. [5], a force platform was used to assess the entire pathological prosthetic gait, which included groups of healthy people with prostheses. In the study that proposes the application of the GRF method by B. Samadi et al. [4] and, when it comes to the reconstruction of the foot-to-ground reaction forces from force platform records, the results suggested the efficient application of this method in the recovery of corrupted data due to incorrect 
stepping on a force platform while performing a certain analysis [6]. Some other studies have the objective of developing dynamic calibration methods $[7,8]$, considering that the static method is the most used due to its low cost.

It is evident that, in clinical practice, postural stability is commonly assessed by the balance performance of body oscillation on a force platform. In these analyzes, individuals with different physical characteristics or pathologies are approached and some simplified commercial prototypes [9] are used, which are quite efficient, but limited in terms of the level of force that can be measured. There is a more extensive study in [10] that details, although in a very limited way, the development of a platform used for sports biomechanical evaluation in athletes. In M. J. Ameen et al. [11], the authors focused on evaluating and analyzing the forces obtained in rotational movements of sports activities using a circular force platform and the LabView software as an interface for data processing and analysis. They claim that the developed prototype can also be used in studies including torque, acceleration, displacement and others that allow measuring the performance of athletes.

Force platform designs that are applied in clinical gait analysis [12] are common, although they present weak details of the development process and a greater focus on data analysis and visualization. Finally, calibration aspects must always be addressed [7,8], including the development of new dynamic models that allow the global calibration of the force platform $[13,14]$.

\section{Literature Survey}

Force platforms have several manufacturing and precision characteristics. Although there are a considerable number of initiatives regarding its use, there are few that present the development of new prototypes and fewer are the works that perform a detailed description of the process. Table 1 presents some of the initiatives that include the development of force platform projects in the literature.

Table 1. Force platform project-applications and technologies.

\begin{tabular}{|c|c|c|c|c|}
\hline No. & Plataform Type & Technologies & Application & Reference \\
\hline 01 & force plates FP4060-07 (square) & $\begin{array}{c}\text { strain gauge } \\
\text { technology/load transducers. }\end{array}$ & vertical GRF & {$[5]$} \\
\hline 02 & $\begin{array}{l}\text { force platform developed at BioLab } \\
\text { in Roma Tre University (square) }\end{array}$ & electro-mechanic actuator. & clinical applications & [6] \\
\hline 03 & standard force platform (square) & $\begin{array}{l}\text { strain gauges in each wheatstone } \\
\text { bridge of each composite sensor. }\end{array}$ & postural balance analysis & [9] \\
\hline 04 & standard force platform (square) & $\begin{array}{c}\text { load cells (beam type), an } \\
\text { amplifier, data } \\
\text { acquisition device. }\end{array}$ & GRF & [10] \\
\hline 05 & standard force platform (square) & load cells (beam type) & $\begin{array}{l}\text { throwing and shifting } \\
\text { forces due to rotation } \\
\text { analysis }\end{array}$ & [11] \\
\hline 06 & 3D platform system & $\begin{array}{l}\text { Structure of the flexible } \\
\text { sensor array }\end{array}$ & $\begin{array}{l}\text { plantar pressure } \\
\text { distribution } \\
\text { measurement } \\
\text { ground reaction force }\end{array}$ & [12] \\
\hline 07 & standard force platform (square) & $\begin{array}{l}\text { load cell (beam type) and } \\
\text { wheatstone bridge. }\end{array}$ & $\begin{array}{l}(\mathrm{GRF}) \text { and displacement } \\
\text { of the center of pressure } \\
(\mathrm{COP})\end{array}$ & [15] \\
\hline 08 & modular force platform & & $\begin{array}{l}\text { gait analysis of children } \\
\text { and neurologic patients }\end{array}$ & [16] \\
\hline 09 & $\begin{array}{l}\text { stabilometric force platform (model } \\
\text { PF2002; SATEL SARL, } 6 \text { rue du } \\
\text { limousin-31700 blagnac; france) }\end{array}$ & load cell (SP4 mark HBM) & $\begin{array}{l}\text { measuring quiet } \\
\text { stance and dynamic } \\
\text { standing balance in } \\
\text { healthy subjects }\end{array}$ & [17] \\
\hline
\end{tabular}


The studies on postural analysis are focused only on the use of force platforms [18-27] and are much more numerous, differently from the projects and research that show greater emphasis on the development of these platforms. The works analyzed in [5,6,9-12,15-17] present descriptions that are very superficial and difficult to reproduce, in addition to all making use of load cells for commercial use, significantly increasing the cost of prototypes.

Finally, and as evidenced in the literary review of Table 1, it is noted the difficulty in finding studies that include the complete and detailed design of force platforms, regardless of the technique or technology to be used, and that stimulate their quick and easy reproduction, as well as the customization of these instruments. The lack of more detailed studies ends up requiring the adaptation of postural analysis techniques to high-cost electronic devices and commercial force platforms that are difficult to customize to meet the demands of precision, resistance, dynamics and maximum load. It should be noted that, in most cases, all these aspects are necessary for conducting innovative clinical studies.

In this work, each of the processes involved in the design, simulation, fabrication, and testing of a low cost extensometric multiaxial force platform is described in detail. The objective is to facilitate the reproduction of this type of instrument, improvement, and suitability for new clinical projects at a low cost. All stages, 3D designs, schematics and source codes are shared throughout this work.

\section{Materials and Methods}

\subsection{An Architecture Overview}

The development of mechanical devices requires adequate attention in their measurements and analysis of the efforts applied to the elements that are part of the device structure. In general, all equipment and instruments are built from a series of structural calculations. Thus, it is possible to determine the maximum load allowed by the part and to consider the safety factor for analyzes of fatigue, rupture and resonance frequencies of the material, also known as modal analysis [28].

The development of the project begins with a functional representation (Figure 1) of all the processes involved, its execution flow and emphasizing the main elements that determine the division of the device's prefabrication steps.

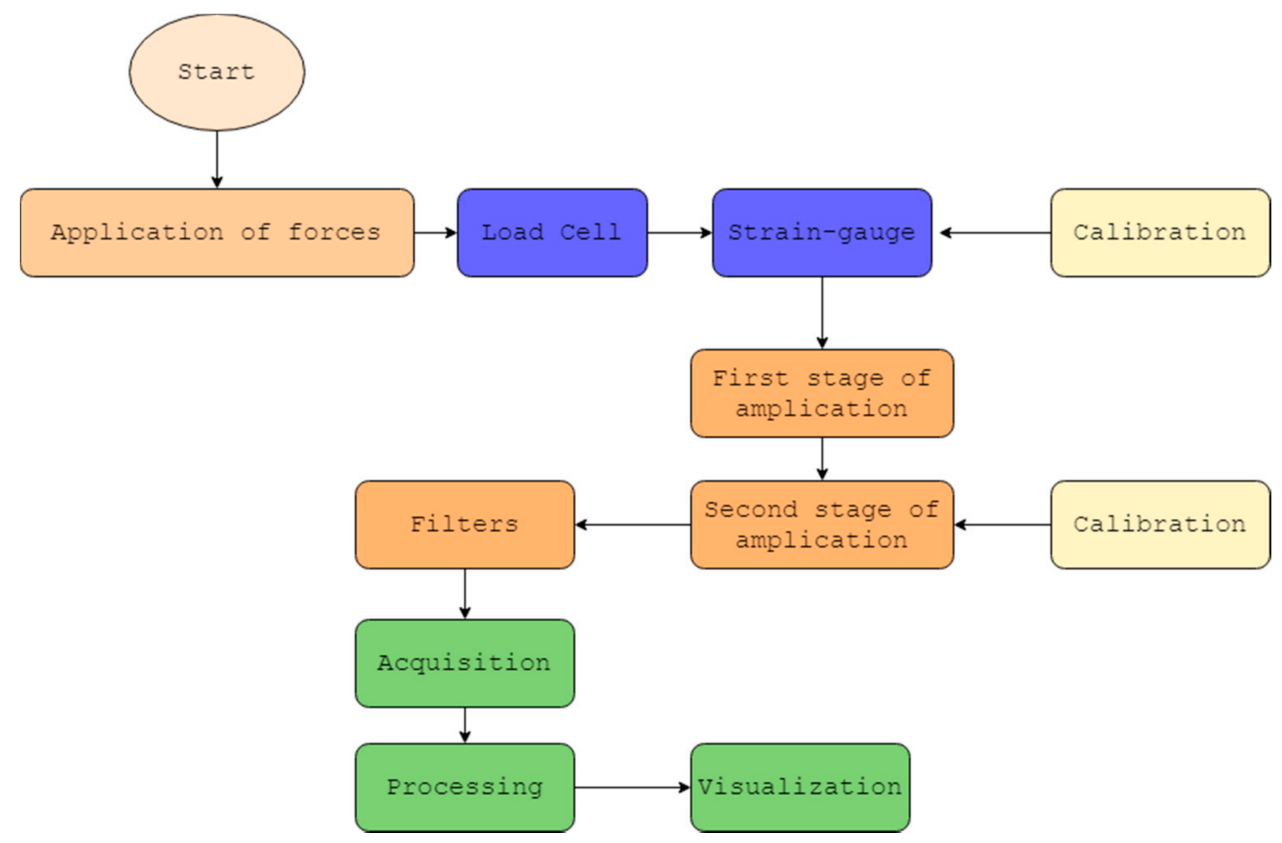

Figure 1. Representation of the functional flow for the design of the force platform.

The following are the steps that correspond to the prefabrication phase of the extensometric multiaxial force platform (Figure 2), which are: 
- The design of the load cells;

- Simulation and optimization;

- Evaluation and optimization of the force platform physical structure;

- Sensor positioning project (strain gauges);

- Implementation of simulated structures and systems.

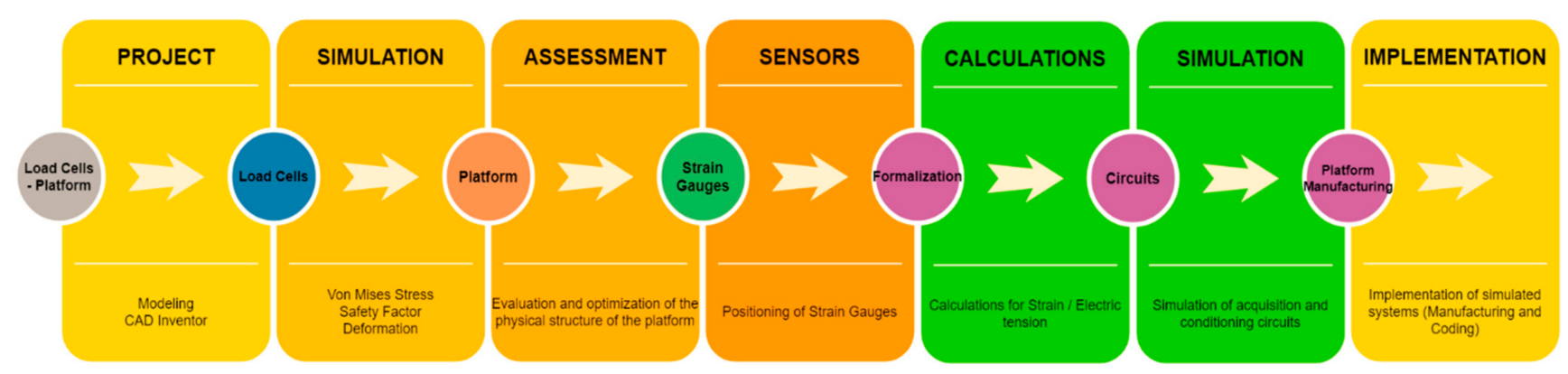

Figure 2. Representation of the execution flow of the prefabrication phase stages.

\subsection{Design and Manufacture of the Force Platform}

In this work, the sensitivity improvement of the biomechanical device is highlighted, as well as the reduction of manufacturing costs when compared to the already existing force platforms.

In this section, there is a step-by-step description of the adopted techniques, tools and models built, which are detailed and made available to facilitate the reproduction of the project by other researchers.

\subsubsection{Platform Design}

The 3D design of the physical structure of the force platform was performed using the Autodesk Inventor ${ }^{\mathrm{TM}}$. In this project, the force platform was divided into 3 parts:

- Lower and upper bases;

- Load cells;

- Load cell mounting and bearing bracket

1. Lower and Upper Bases

The upper and lower bases are dimensioned considering the area necessary to accommodate a person with the feet aligned to the hip. Hence, the dimensions of the bases are $400 \times 400 \mathrm{~mm}$ (Figure 3).
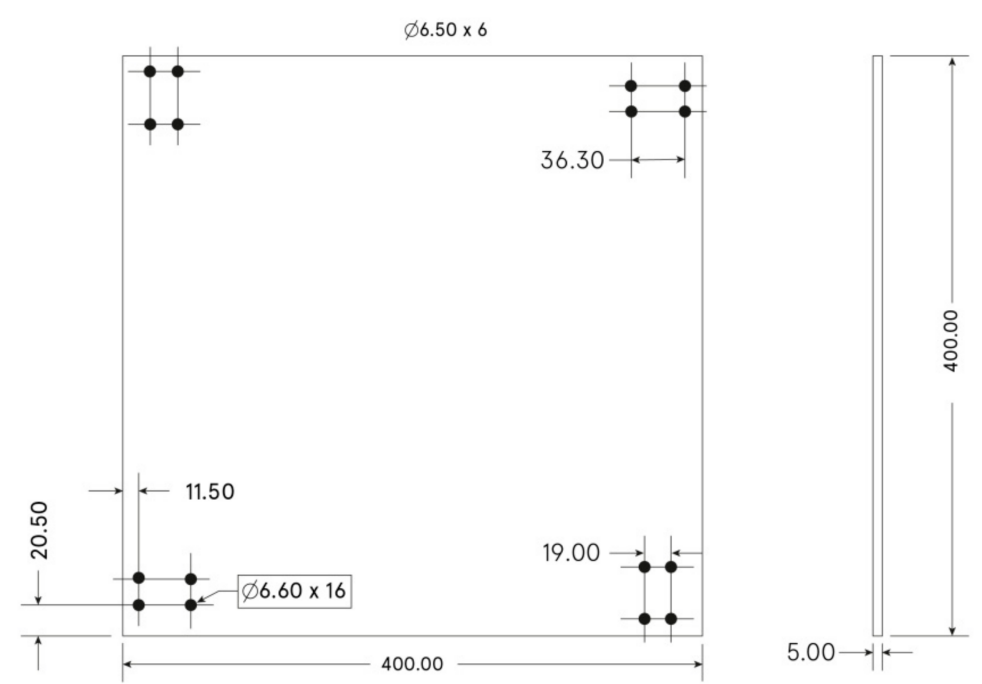

Figure 3. Design of the force platform bases—detailing and dimensions. 
Both bases (upper and lower) basically differ in two aspects: the type of material and the thickness. The upper base is composed of naval aluminum AN5052, due to the proven ability to conduct forces by load cells $(400 \times 400 \times 10 \mathrm{~mm})$. The bottom base is made of AISI 1020 steel, as it is a ductile material and contributes to the stability and fixation of the platform $(400 \times 400 \times 5 \mathrm{~mm})$.

\section{Load Cells}

The material chosen for the manufacture of load cells (Figure 4) is AISI304 stainless steel. The choice was made based on its hardness and elasticity coefficient, which together improve the measurement of electrical signals in the strain gauges [29].

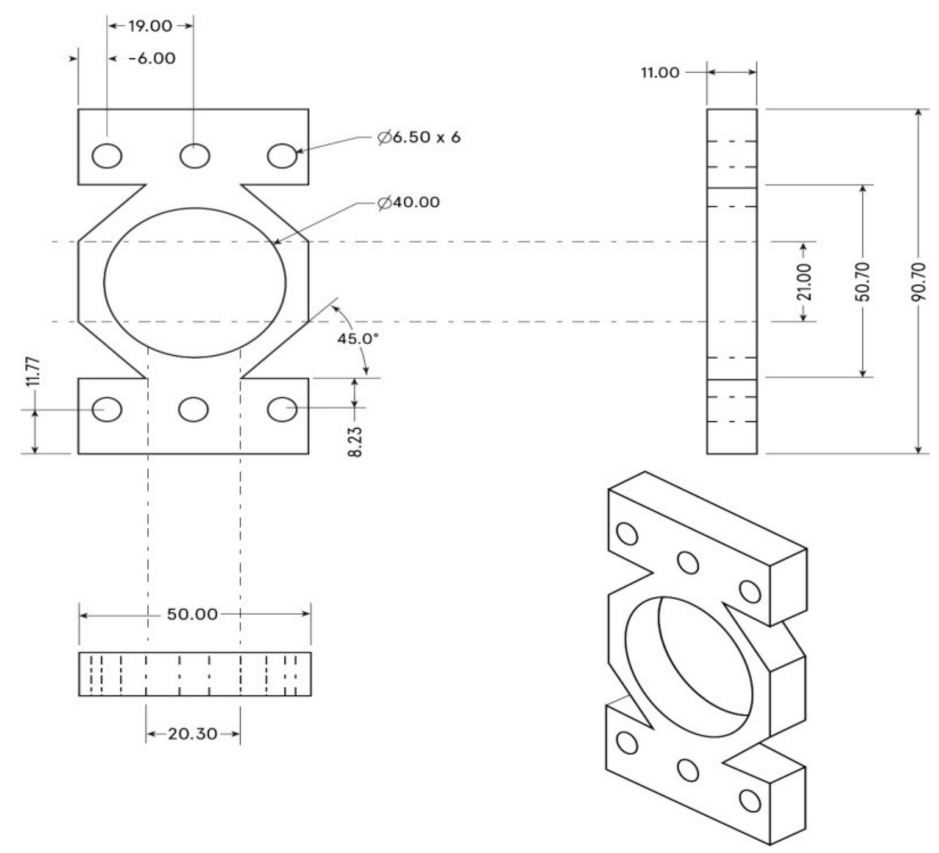

Figure 4. Load cell design, detailing and dimensions.

3. Load Cell Mounting and Bearing Bracket

The brackets are designed for fixing the load cells (Figure 5). For manufacturing, a $3 / 4^{\prime \prime} \times 1 / 8^{\prime \prime}$ carbon steel angle bracket is used, with well-dimensioned holes (the diameter of the holes is the same as the diameter of the load cells).

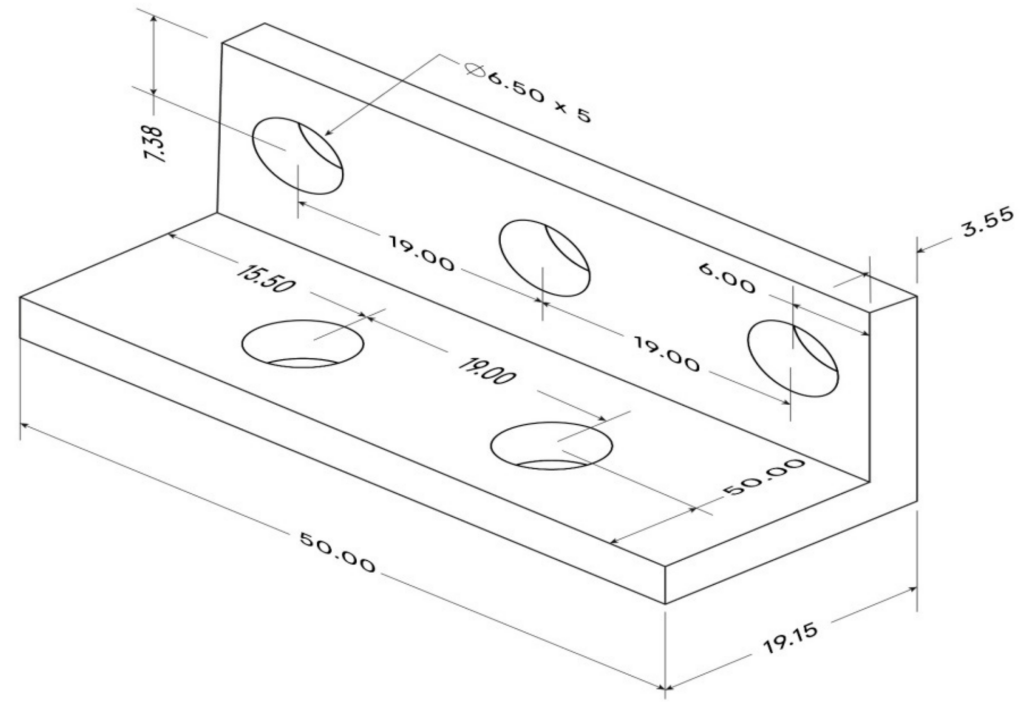

Figure 5. Bearing brackets-detailing and dimensions. 


\subsubsection{Design of the Conditioning Circuit and Amplification}

The strain gauge [29] presents extremely low resistance variations (in the milli ohms range). Therefore, a Wheatstone bridge [30] is used to obtain these resistance variations. With the proportional change of the impedances that are part of the circuit, the bridge loses its equilibrium state and there is a potential difference between the blocks. This variation, although small, can be easily detected when coupled to an amplifier circuit.

The design of the Wheatstone bridge scheme can be seen in Figure 6. Figure 6a represents the initial distribution given to the strain gauge in the load cell, and in Figure $6 \mathrm{~b}$, the electrical circuit of the bridge can be observed. The analyzes performed for the disposition of the strain gauges are presented in Section 2.2.3 (a).

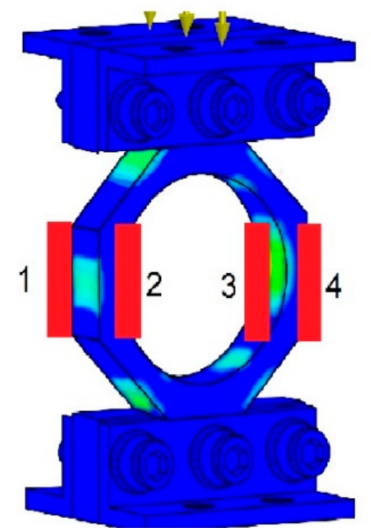

(a)

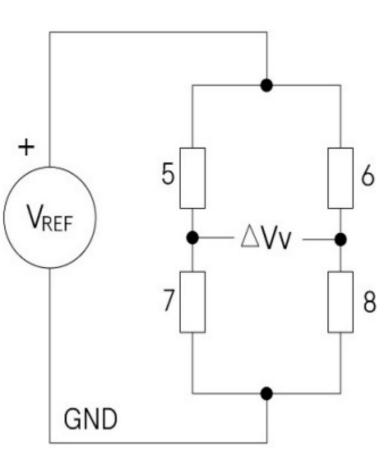

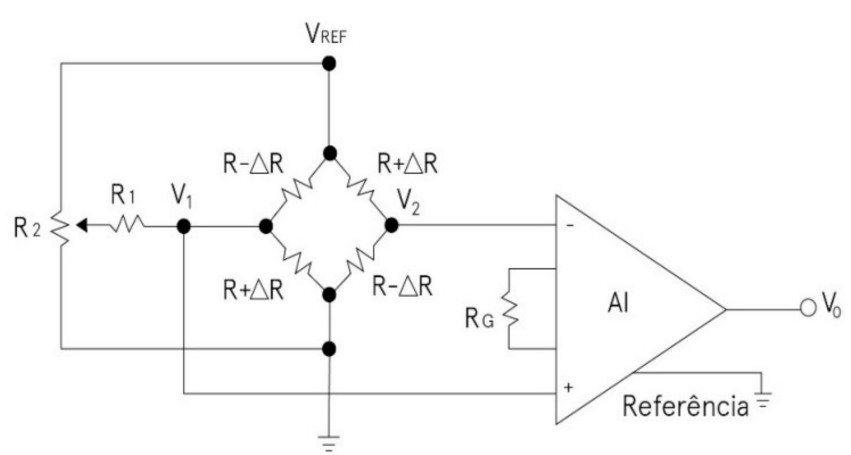

(b)

Figure 6. (a) Distribution of strain gauges on load cell. (b) Wheatstone bridge in differential mode with four strain gauges.

The equations used to calculate the voltages in the circuit are described as follows (Equations (1)-(3)):

$$
\begin{gathered}
V_{1}=V_{R E F} \frac{R+\Delta R}{R+\Delta R+R-\Delta R}=V_{R E F} \frac{R+\Delta R}{2 R} \\
V_{2}=V_{R E F} \frac{R-\Delta R}{2 R} \\
V_{0}=A \frac{\Delta R}{R} V_{R E F}
\end{gathered}
$$

where $R$ is the constant resistance of each strain gauges; $\Delta R$ is the resistance variation given by the mechanical deformation; $V_{R E F}$ is the supply voltage of the bridge; and $A$ is the instrumentation amplifier gain.

Therefore, it can be concluded that, in an ideal scenario, where the Wheatstone bridges provide perfect balance, the implementation of the following circuit shown in Figure 7 would be adequate. 


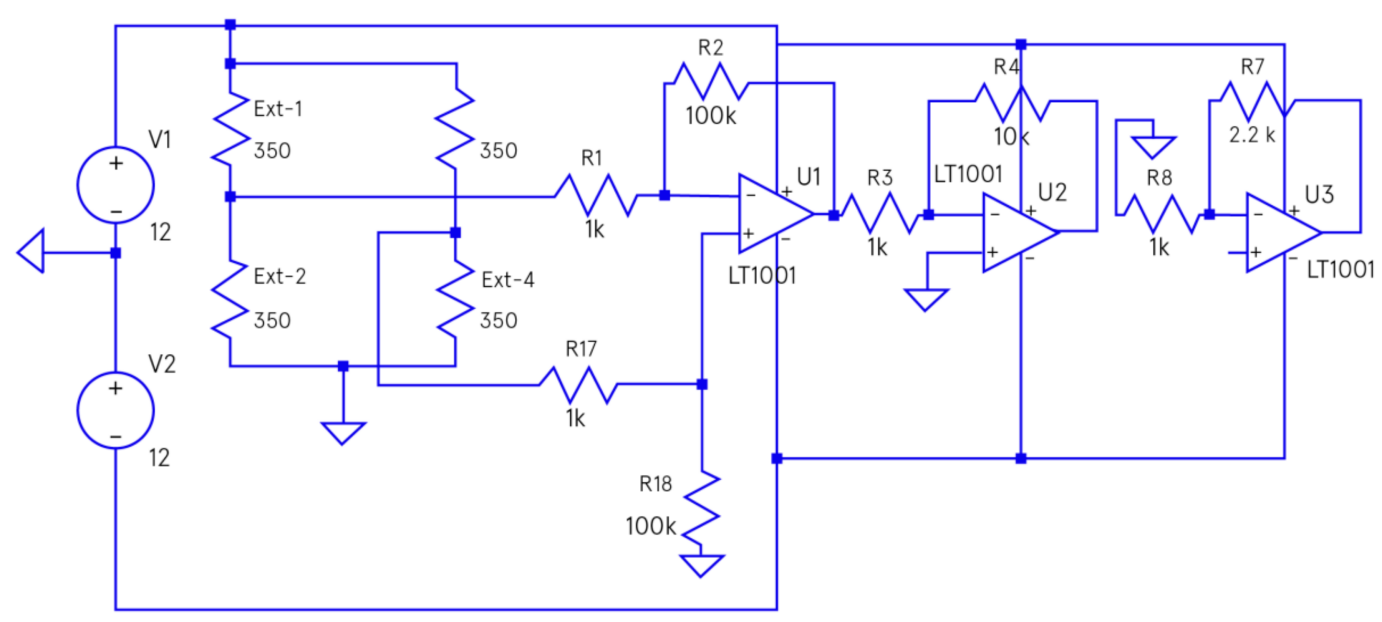

Figure 7. Ideal amplification circuit for the Wheatstone bridge.

\subsubsection{Component Simulations and Validation}

In this section, the formalisms used in the stress, safety and deformation experiments performed on the load cell elements and the complete structure of the extensometric multiaxial force platform will be described.

- Von Mises Stress Analysis

The Von Mises Stress test is known as the equivalent force applied to each infinitesimal element in the part. Such force is given by the combination of the main stresses on the $X, Y$ and $Z$ axes. The equation that defines Von Mises Stress is given by (Equation (4)) [31].

$$
\sigma_{v}=\sqrt{\frac{\left(\sigma_{11}-\sigma_{22}\right)^{2}+\left(\sigma_{22}-\sigma_{33}\right)^{2}+\left(\sigma_{33}-\sigma_{11}\right)^{2}+6\left(\sigma \frac{2}{12}+\sigma \frac{2}{23}+\sigma \frac{3}{31}\right)}{2}}
$$

where $\sigma$ represents the stresses in the different axial components.

- Safety Factor Analysis

The safety factor indicates the ratio between the maximum stress supported and the current stress applied to the part. This value is necessary to assess structural failures arising from the application of forces. Its equation is given by (Equation (5)):

$$
F . S=\frac{\sigma_{\text {rup }}}{\sigma_{\text {adm }}}
$$

where $\sigma_{\text {rup }}$ represents the breaking stress (maximum accepted by the part before breaking); $\sigma_{a d m}$ is the voltage allowed by the part (the current applied voltage).

- Strain Analysis

Deformation analysis is crucial for this project once electrical signals can then be obtained to characterize the flight time and postural analysis of individuals.

Deformation is given by a dimensionless value, which relates the variation in length to the initial length. This value will be used directly on the equations related to the electrical resistance of the strain gauge. The equation used to characterize the deformation is given by Equations (6) and (7):

$$
\begin{gathered}
\text { Transverse Deformation }\left(\varepsilon_{t}\right)=\frac{\Delta d}{d} \\
\text { Longitudinal Deformation }\left(\varepsilon_{l}\right)=\frac{\Delta l}{l}
\end{gathered}
$$


where $\Delta d$ is the width variation of the piece; $d$ is the initial width of the piece; $\Delta l$ é is the variation in length; and $l$ is the starting length.

From the strain equations, it is possible to obtain the Poisson's ratio equation, which relates the longitudinal and transversal deformations (Equation (8)) [32].

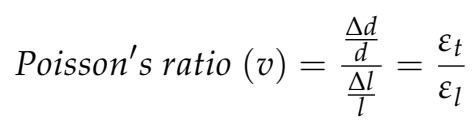

\section{(a) Load Cells}

The data acquisition system is based on the manufacture and use of four hexagonal load cells distributed as support for a rectangular metal base. Each load cell must have four strain gauges distributed to offer thermal compensation and three-dimensional sensitivity. The strain gauges work from the variation of electrical resistance due to deformation. Therefore, a measurement alternative would be to use a Wheatstone bridge for every four sensors.

To validate the design of the load cells as well as their complete viability in the design of the force platform, a simulation environment is required for the design of the structure (Figure 4). The analysis of the load cells is performed individually, thus characterizing the regions with the greatest strain and allowing the identification of the ideal regions for insertion of the strain gauges.

- Von Mises Stress Analysis

The first experiment is carried out applying a load of $700 \mathrm{~N}$, which is shown in Figure 8.
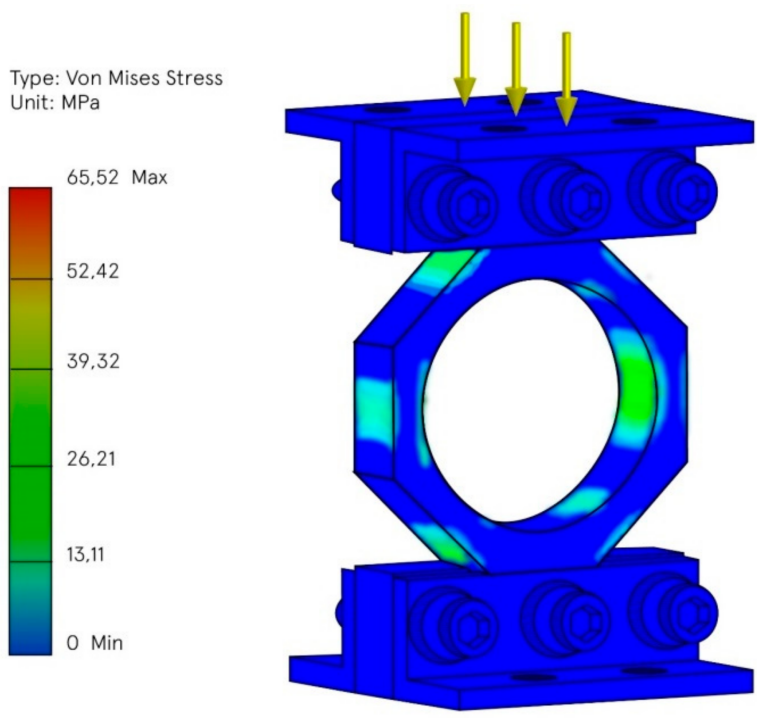

Figure 8. Von Mises Stress Analysis, applying a load of 700 N.

Analyzing Figure 8, it is possible to observe the points of the part that suffer the most equivalent effort and the intensity of the pressure submitted on each infinitesimal part, which makes it possible to compare with the stresses of plastic deformation and rupture of the material used. Table 2 shows the mechanical data for the materials used to feed the simulator when designing the load cells. 
Table 2. Mechanical data of the AISI304 stainless steel.

\begin{tabular}{ccc}
\hline Properties & Value & Units \\
\hline Elastic module & $1.9 \times 10^{+11}$ & $\mathrm{~N} / \mathrm{m}^{2}$ \\
Poisson's ratio & 0.29 & $\mathrm{~N} / \mathrm{A}$ \\
Shear Module & $7.5 \times 10^{+10}$ & $\mathrm{~N} / \mathrm{m}^{2}$ \\
Density & 8000 & $\mathrm{Kg} / \mathrm{m}^{3}$ \\
Tensile strength & $517,017,000$ & $\mathrm{~N} / \mathrm{m}^{2}$ \\
Flow limit & $206,807,000$ & $\mathrm{~N} / \mathrm{m}^{2}$ \\
Coefficient of thermal expansion & $1.8 \times 10^{-5}$ & $1 / \mathrm{K}$ \\
Thermal Conductivity & 16 & $\mathrm{~W} /(\mathrm{m} . \mathrm{k})$ \\
Specific Heat & 500 & $\mathrm{~J} /(\mathrm{kg} . \mathrm{k})$ \\
\hline
\end{tabular}

\section{- Safety Factor Analysis}

Unlike the Von Mises stress analysis, the safety factor summarizes the possibility of failures, showing the direct relationship between the applied stress and the rupture stress. The results of the safety factor when applying a load of $700 \mathrm{~N}$ can be seen in Figure 9.
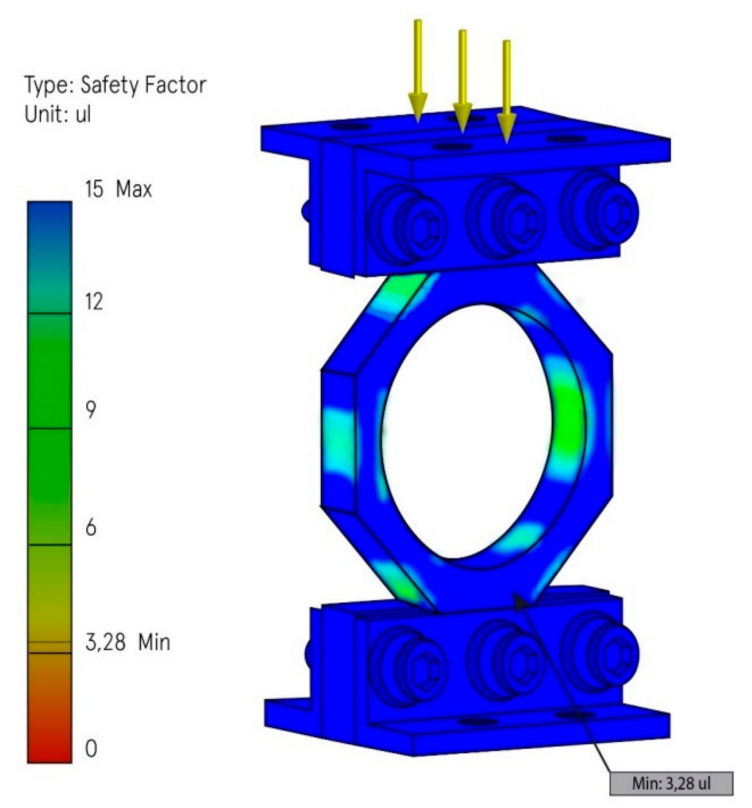

Figure 9. Safety factor applying a load of $700 \mathrm{~N}$.

When analyzing Figure 9, it is evident that the resulting minimum safety factor is equal to 3.28. This means that the current applied voltage is 3.28 times less than the maximum supported voltage. Therefore, the part is free from the possibility of breakage.

\section{- Strain Analysis}

With this analysis, it is possible to verify which points of the material will suffer the greatest deformation effect on the applied load conditions. This is a significant aspect for the current project, as it makes it possible to analyze the proper positioning of the Strain Gauges so that they obtain the greatest possible deformation, transmitting the electrical information with higher precision.

In Figure 10, it is possible to observe the deformation concentration points. On average, the greenish regions have a deformation equal to $1.22 \times 10^{-4}$. This value will be directly related to the sensitivity equation of the Strain Gauge, which is later related to the 
variation in the voltage drop of the sensor. The equation that relates the deformation and the sensitivity of the sensor is given by Equation (9).

$$
G F=\frac{\Delta R / R}{\Delta l / l_{0}}=\frac{\Delta R / R}{\varepsilon}
$$

where GF is the gauge factor (given according to the component); $\Delta R$ is the resistance variation; $R$ is the initial resistance of the component; and $\varepsilon$ is the equivalent strain. Such equation makes it possible to calculate the resistance variation that will be directly linked to the signal acquired by the conditioning and amplification system.

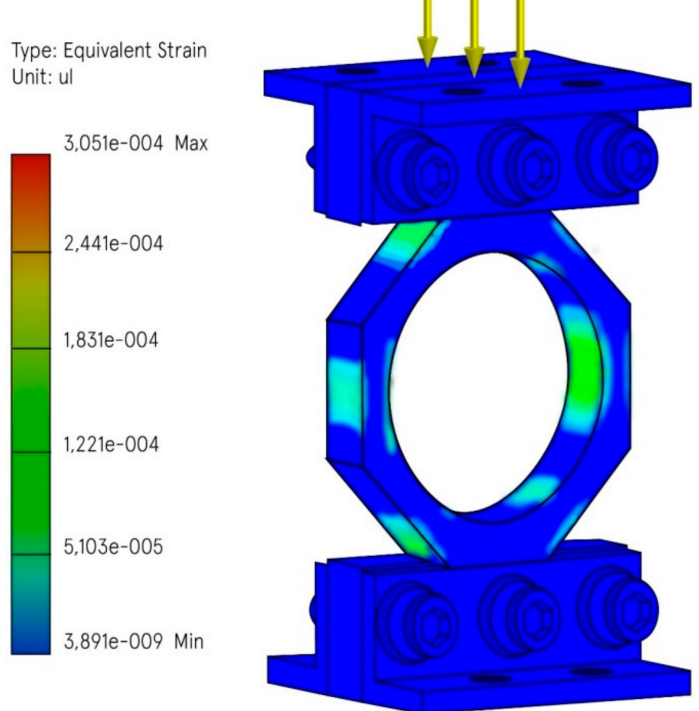

Figure 10. Equivalent strain applying a load of $700 \mathrm{~N}$.

Evaluating the load cell individually to characterize the regions of greatest deformation is necessary to allow an effective location of the ideal regions for insertion of the strain gauges. To confirm the arrangement of the extensometers, the experiment in Figure 10 is repeated, now applying a load of $1000 \mathrm{~N}$ on the load cell.

It is possible to see in Figure 11 the deformation concentration on the sides of the load cell. This confirmation is used as a reference for the positioning of the extensors, as already observed in Figures 6 and 11.

(a)

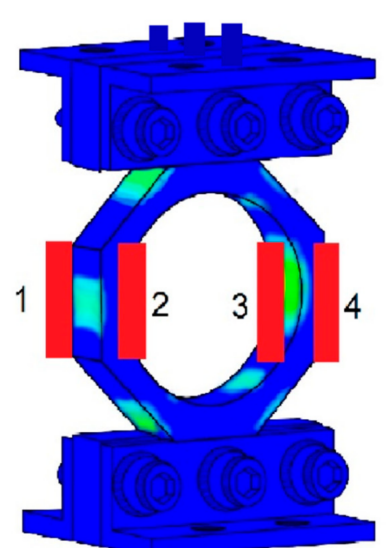

(b)

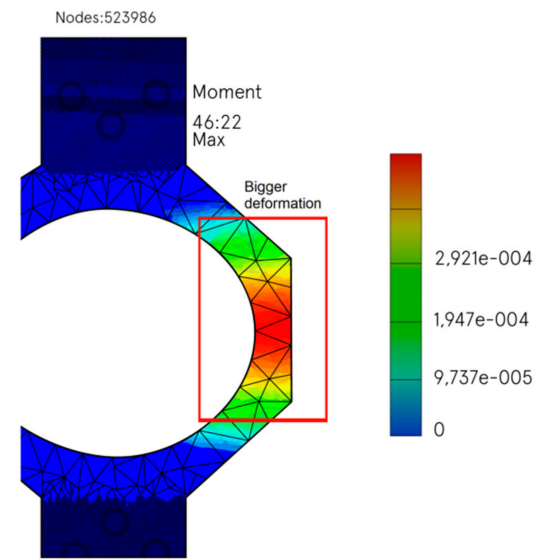

Figure 11. (a) Strain-gauges. (b) Equivalent strain applying a load of $1000 \mathrm{~N}$ (now with Strain-gauges). 


\section{(b) Lower and Upper Bases-Complete Platform}

Autodesk Inventor was used to model and simulate the platform design (Figures 3-5). With the platform properly modeled and assembled in each of its projected parts, it is necessary to evaluate two mechanical characteristics. The first one refers to the regions of deformation concentration in the load cells and the second one, to the maximum loads supported.

\section{- Von Mises Stress Analysis}

For the Von Mises simulation, it is observed (Figure 12) that the load distributions in the cells were concentrated in points closer to the center of the platform (where the force is applied). This was critical to distribute the strain gauges, as the simulation in a single cell does not present or represent the tendency of forces, since the load was distributed symmetrically.

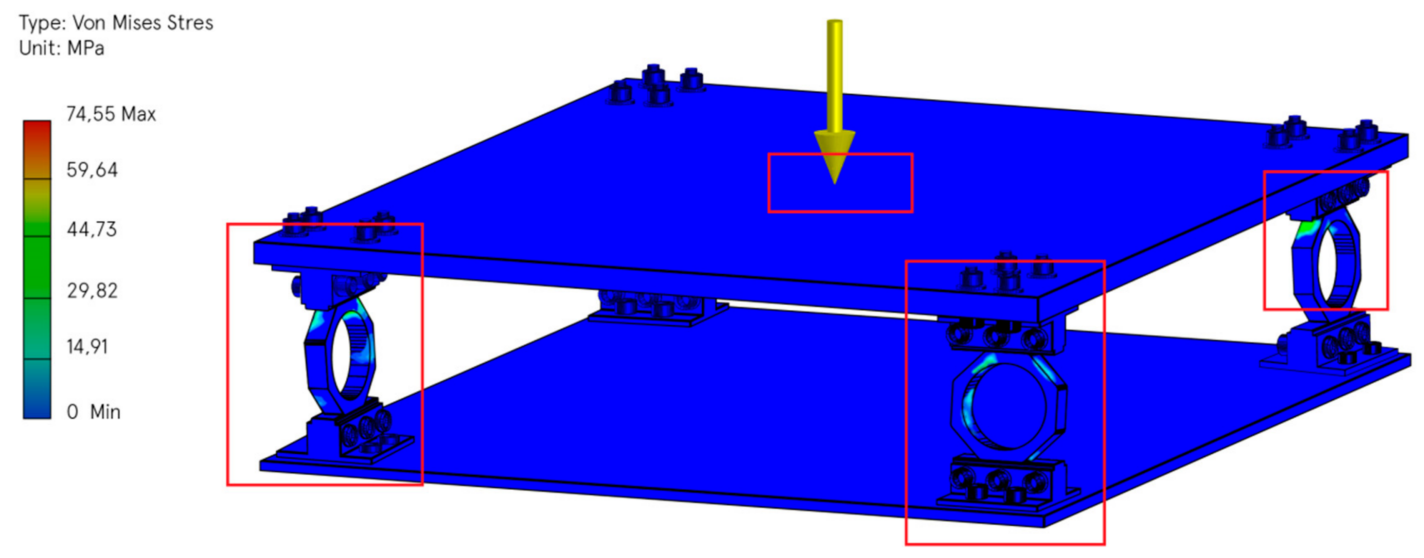

Figure 12. Stress analysis of the structure on the complete platform.

\section{- Safety Factor Analysis}

In Figure 13, the analysis of the safety factor on the complete platform is presented with the application of two $700 \mathrm{~N}$ forces, one at each end of the platform, and the addition of the gravitational force. The analysis of the safety factor is crucial for preventing material breakage under mechanical stress.

\section{Type: Safety Factor}

Uni: ul (Unit Less)

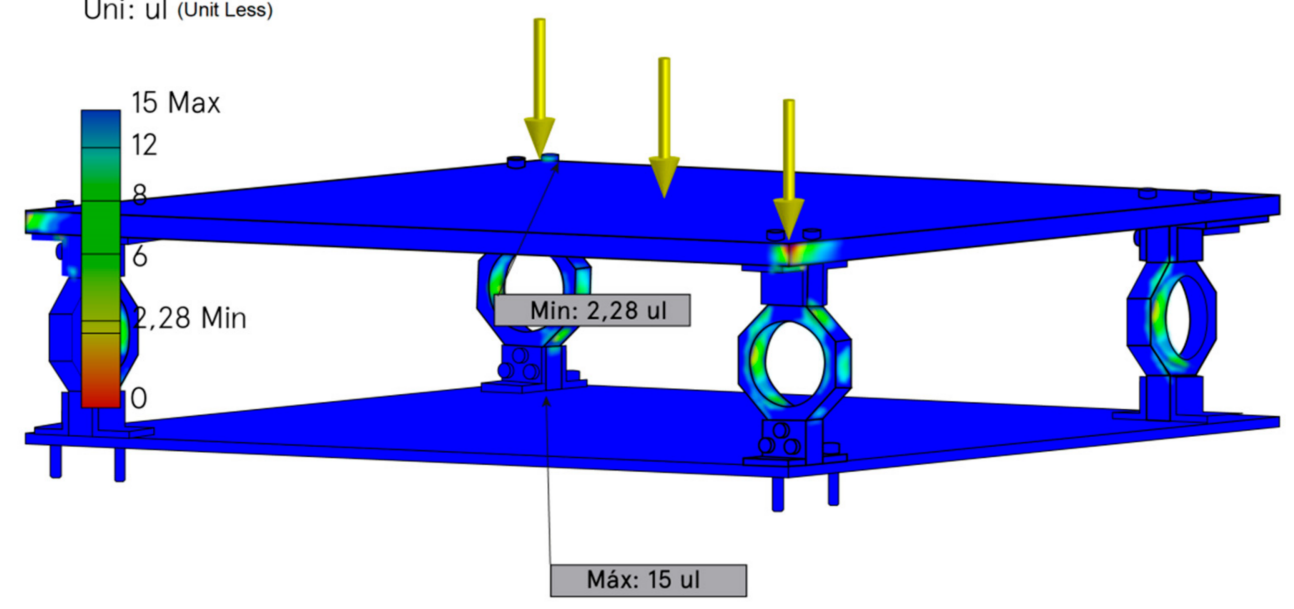

Figure 13. Analysis on the complete platform. 
The calculation of the safety factor is obtained from the relationship between the maximum load supported by the material and the current load applied, as can be seen in Equation (10).

$$
F s=F_{\text {rup }} / F_{a d m}
$$

where $F_{\text {rup }}$ is the breaking force of the material, and $F_{a d m}$ is the allowable force (current force applied to the material).

Examining the results in Figure 13, safety factors very close to 1 or less than 1 are considered risky factors, as the material will act at its load limit. From the simulations, it was observed that, for the application of a static equivalent load of $1400 \mathrm{~N}$ (700 N at each end), the minimum safety factor was 2.28. This means that the material is operating at less than half the maximum supported force; therefore, there is no risk of early breakage.

\section{- Strain Analysis}

In the strain analysis, a central load of $1000 \mathrm{~N}$ is applied to the platform, which is approximately equivalent to $5 \mu \mathrm{m}$. In the simulation (Figure 14), the most reddish regions vary from 80 to $100 \mu \mathrm{m}$. This happens because of the changes made in the geometry of the load cells in relation to the reference geometry. However, if the safety factor margin is greater than 2, greater deformations will provide better results in data acquisition. It is important to note that these deformations allow greater variation in electrical resistance, which, in turn, is directly linked to the variation in electrical voltage in the acquisition circuit.

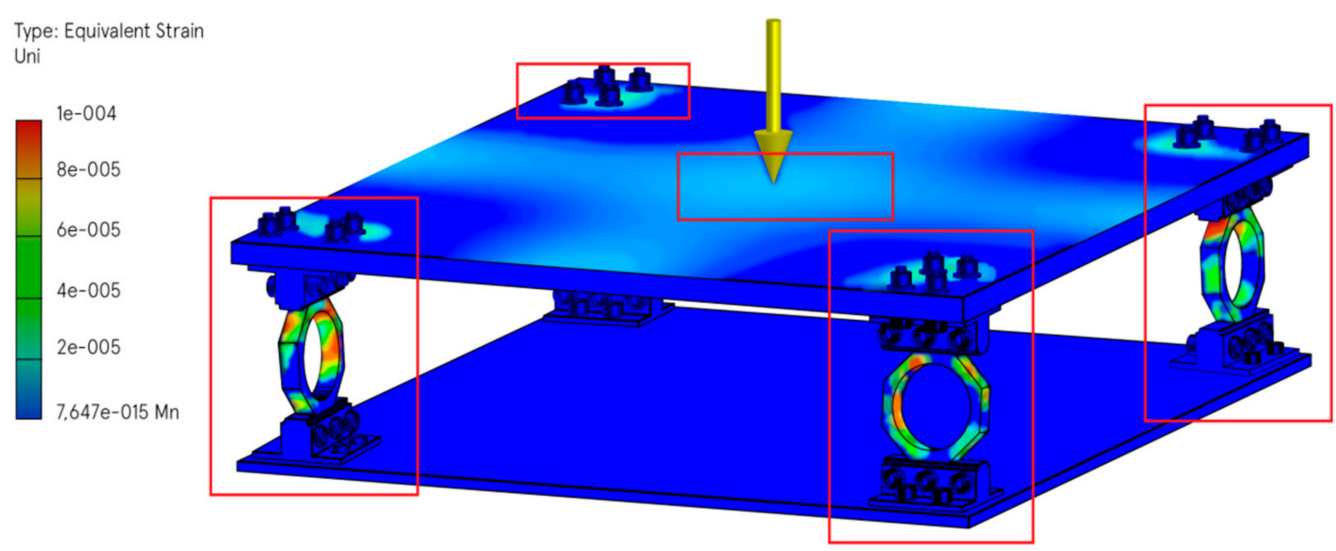

Figure 14. Strain analysis applying a central load of $1000 \mathrm{~N}$.

\section{(c) Amplification Circuit for Wheatstone Bridge}

In the design of an amplification circuit, some procedures are repeated to validate the efficiency of the circuit regarding the function that it must fulfill with the component where it will be implemented. In Section 2.2.2 (Figure 7), an ideal amplification circuit for the Wheatstone bridge is presented. However, to validate the circuit application in this project, it is necessary to simulate it over several resistance variations.

In the real system (Figure 7), there are small variations in resistance due to several factors, such as the length of the connectors and manufacturing errors of the components.

To exemplify the influence of the bridge imbalance in the last amplification stage, a simulation was performed with a variation of only $2 \mathrm{ohms}$ in one of the extensometers on the bridge. The output signal for the balanced circuit is presented in Figure 15. 


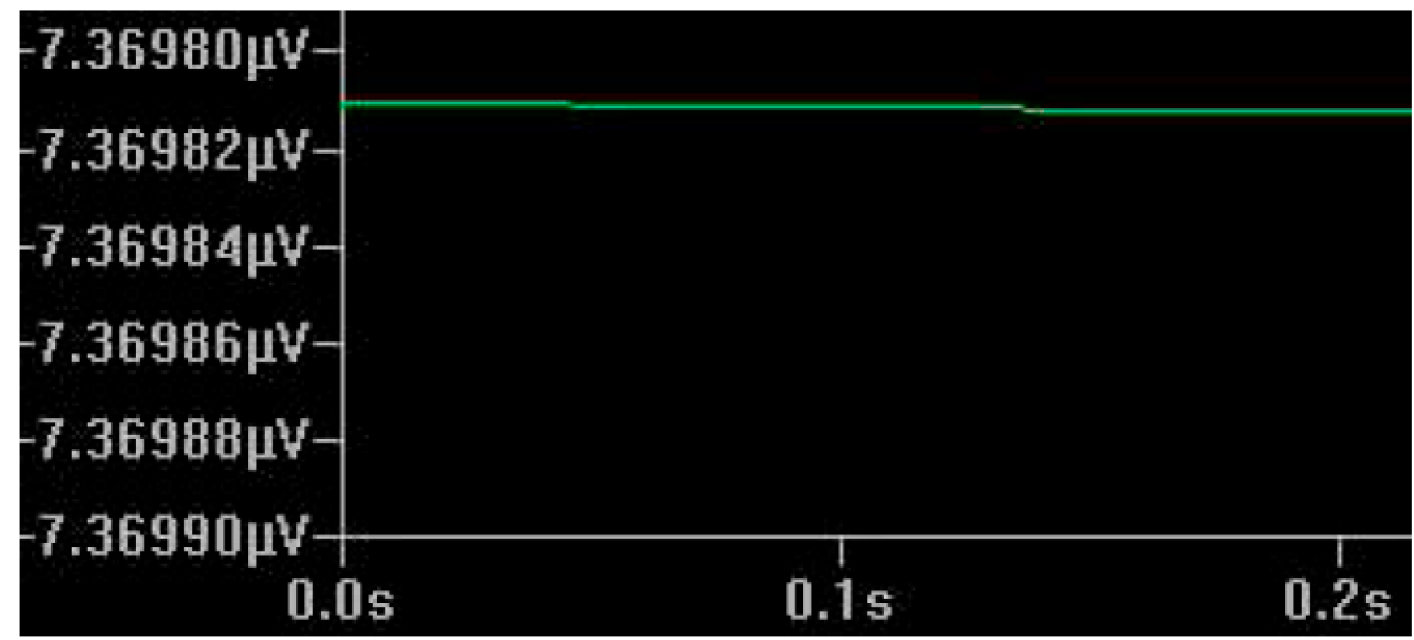

Figure 15. Circuit response for the ideal balanced bridge.

Therefore, when considering the stages of amplification with a total gain of 2000 times the input signal, the output signal with $7 \mu \mathrm{V}$ can be easily disregarded due to its tiny magnitude when compared to the total gain.

However, observing the circuit for the ideal bridge, in Figure 16 it is presented the amplification sequence in the stages when there is a difference of only 2 ohms in one of the extensometers.

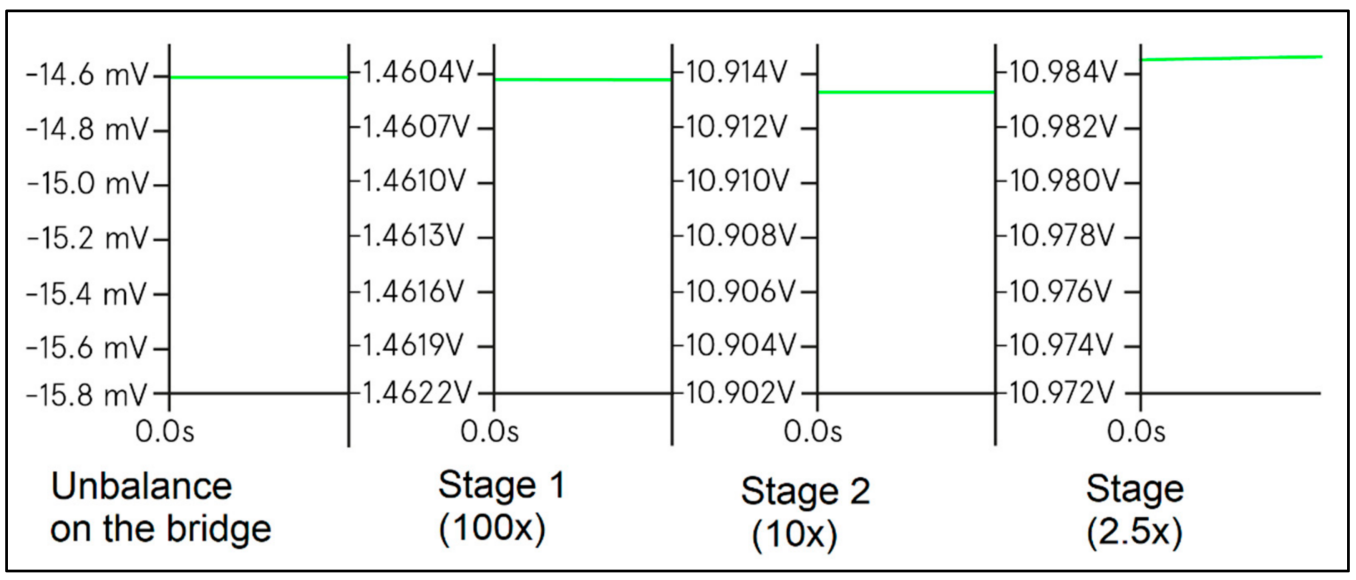

Figure 16. Voltage response in the amplification stages for the circuit with bridge imbalance.

In Figure 16, it is possible to observe that the variation of only 2 ohms reflected a small variation of $14.6 \mathrm{mV}$ in the Wheatstone bridge. At first, such tension appears to be insignificant; however, when reaching the second amplification stage, it can be observed that there was saturation of the operational amplifier, since the gain of the input signal exceeded the amplifier's power.

Finally, due to the extremely small voltage variations in the bridge, it was necessary to build several amplification steps with the appropriate offset adjustments and removal of the DC level generated by the bridge instability (constant difference of the bridge).

In Figure 17, the circuit for the equivalent system applied to each load cell is presented. 


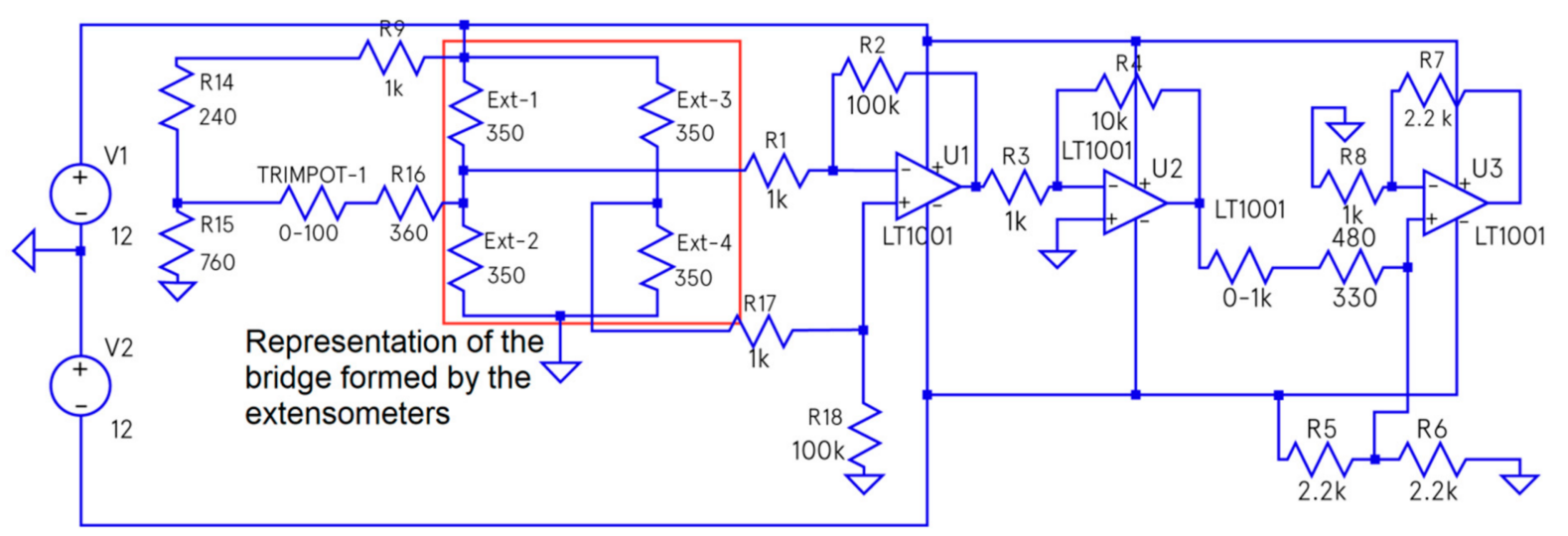

Figure 17. Equivalent circuit used in the load cells.

Finally, when observing the equivalent circuit, there are three essential steps:

- Acquisition of the signal from the Wheatstone bridge;

- DC level control (offset);

- Amplification stages.

The circuit was divided into three stages of amplification, and each stage includes a distinct amplification gain to adapt the signal without saturation of the amplifiers.

\subsubsection{Sampling System}

At the end of the signal amplification and filtering stages, it is necessary to perform its sampling. Therefore, a low-cost development platform known as Arduino UNO was used, which includes a digital analog converter with 10 bits of resolution, enabling the sending of data via serial interface to the computer where the information will be properly processed.

When acquiring the data, some characteristics must be considered, such as the resolution of the digital converter, which must not be too high. Therefore, the oversampling technique will be used, which corresponds to the increase in the sampling rate of the circuit. Then, it will be necessary to evaluate the harmonic content of the characteristic signal from the Wheatstone bridges. A mathematical representation of the process can be formulated following Equation (11).

$$
f(x)=\frac{a_{0}}{2} \sum_{n-1}^{\infty}\left(a_{n} \cos \left(\frac{m \pi t}{T}\right)+b_{n} \operatorname{sen}\left(\frac{n t \pi}{T}\right)\right.
$$

The next step was to complete the spectral analysis in a digital oscilloscope, which allowed the characterization of the components in terms of frequency and amplitude. In addition to the Fourier analysis, the waveform generated by the jumps (jump over the force platform) was also observed. Then, the maximum necessary frequency to be sampled to extract the appropriate information about the jump was characterized. From such experiments, it was observed that the maximum frequency does not exceed $50 \mathrm{~Hz}$.

After characterization, Nyquist's theorem is applied, stating that the sampling frequency must be at least twice the highest harmonic frequency with considerable amplitude.

$$
F_{\text {sampling }} \geq 2 \times F_{\text {max }}
$$

Therefore, knowing the Nyquist frequency, it is possible to configure the frequency of the digital analog converter, in addition to enabling the analysis to perform oversampling. Consequently, the microcontroller was configured to perform sampling every $10 \mathrm{~ms}$ $(100 \mathrm{~Hz})$, respecting the Nyquist rule, given that the maximum signal frequency is $50 \mathrm{~Hz}$.

To complete the sampling cycle, it is necessary to send the data to the computer. For this purpose, the Arduino serial interface was used. To send the information, it was necessary to define the package structure, which includes information about the load cells 
and the preambles for the start and end of the package to ensure that it was sent completely. Hence, the data package has the structure shown in Figure 18.

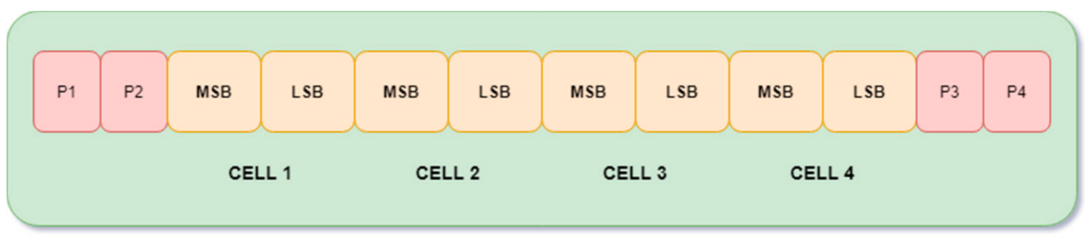

Figure 18. Data packet structure for sending data via serial interface.

\section{Results}

\subsection{User Interface}

Data processing will be based on the temporal analysis of the signal obtained by the ADC converter. From the derivation of the signal, it will be possible to analyze the points with the greatest variation, making it possible to detect the moments when the athlete started and returned on the platform (dynamic of the jump on the force platform). From the start and end points, it is possible to analyze the duration time between peaks, which characterizes the athlete's flight time. From the flight time, it will be possible to apply equations from classical physics and determine various information pertinent to the athletes' analysis, such as the starting power, vertical displacement speed, mechanical impact and displacement of the center of mass.

The data presented were defined based on scientific articles related to the force platform with an emphasis on jumping. Some of the formulas that will be presented later use the athlete's flight time as an unknown number. To calculate the flight time, it is necessary to vary the time between the blue point (dt3, observed in the graph of Figure 19), the contact point after the jump and the $\mathrm{dt} 1$, moment of the athlete's jumping on the platform.

$$
\text { Flight time }=\text { Time of impulse for jump - time on jump }
$$

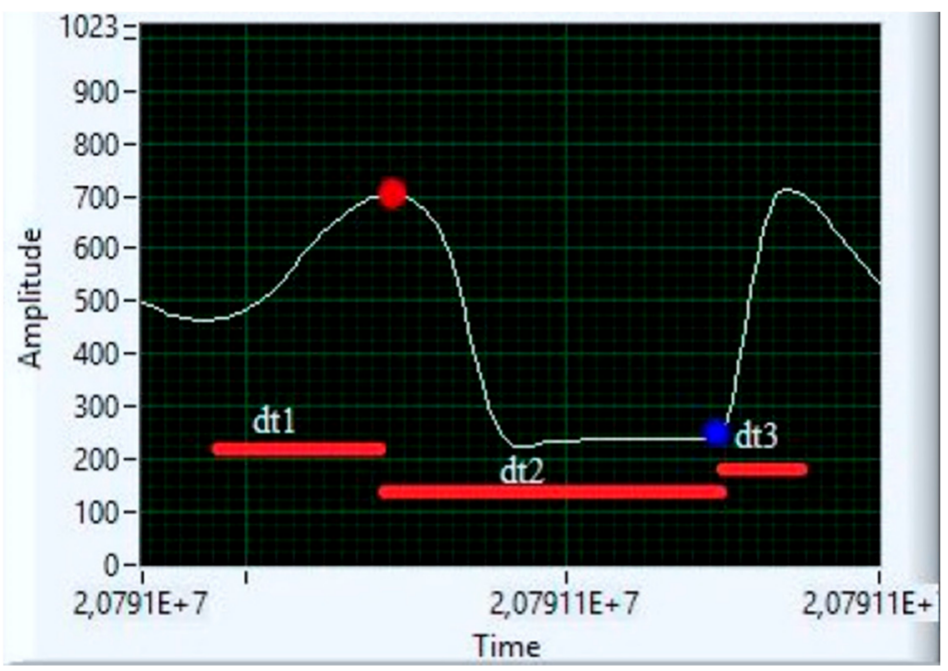

Figure 19. Analysis of one jump.

Therefore, after obtaining the flight time, we can perform the following calculations: Initial Speed

$$
V 0=\frac{9.8 \times \text { Flight time }}{2}
$$


Jump Height

$$
H=(\text { Flight time } \times V 0)+\left(\frac{9.8 \times \text { Flight } t \text { time }^{2}}{2}\right)
$$

In Figure 19, it is possible to observe three steps during the jump:

- Time of impulse for the jump, moment when the body prepares to jump (dt1);

- Flight time, moment when the body is in the air (dt2);

- Fall time, moment when forces dissipate (dt3).

Figure 20 represents a probable scenario for using the extensometric multiaxial force platform. The validation of the function is guided in the use of the platform for analysis of flight time of volleyball athletes.
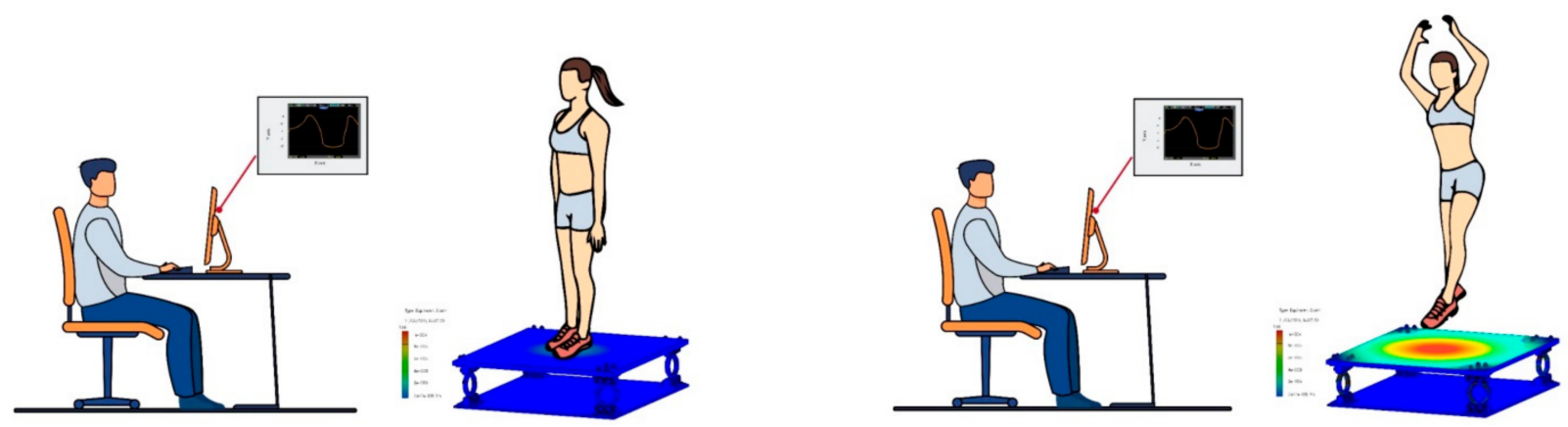

Figure 20. Representation of a jump-analysis on the force platform.

In Figure 21, it is possible to observe the functions of the athletes' flight analysis interface (analysis function and jump characterization). Interface number 1 corresponds to the visualization of the signal generated as a result of a jump as a function of time. At interface number 2, the graph shows the signal counting the number of jumps and their intensity. Finally, at interface number 3 , it is possible to monitor the force exerted and calculated on each load cell (four load cells).

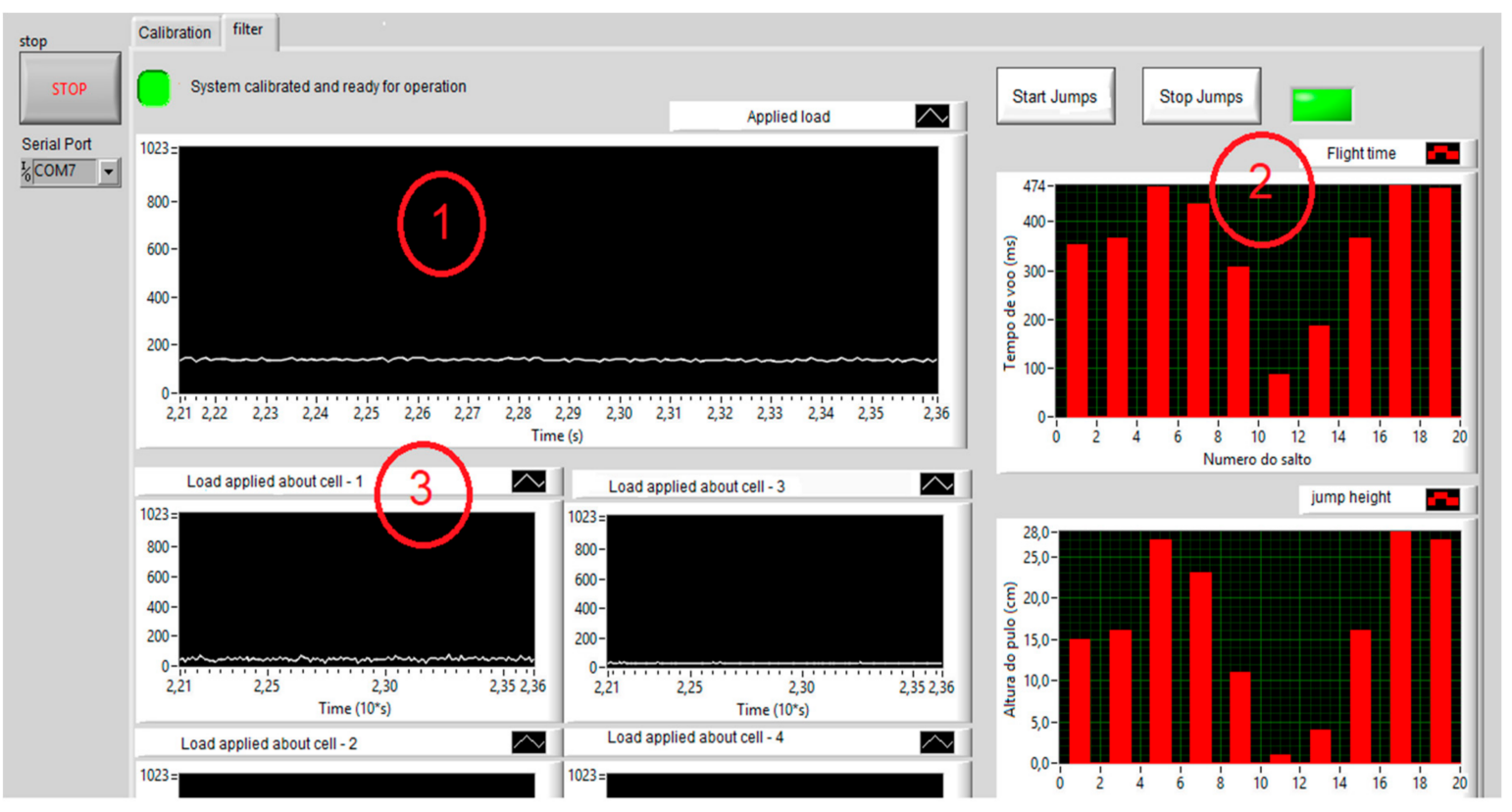

Figure 21. User interface. 
The calibration process is an essential event and is necessary for the correct reading balance in the forces received, calculated and processed by the extensometric multiaxial force platform (Figure 22).

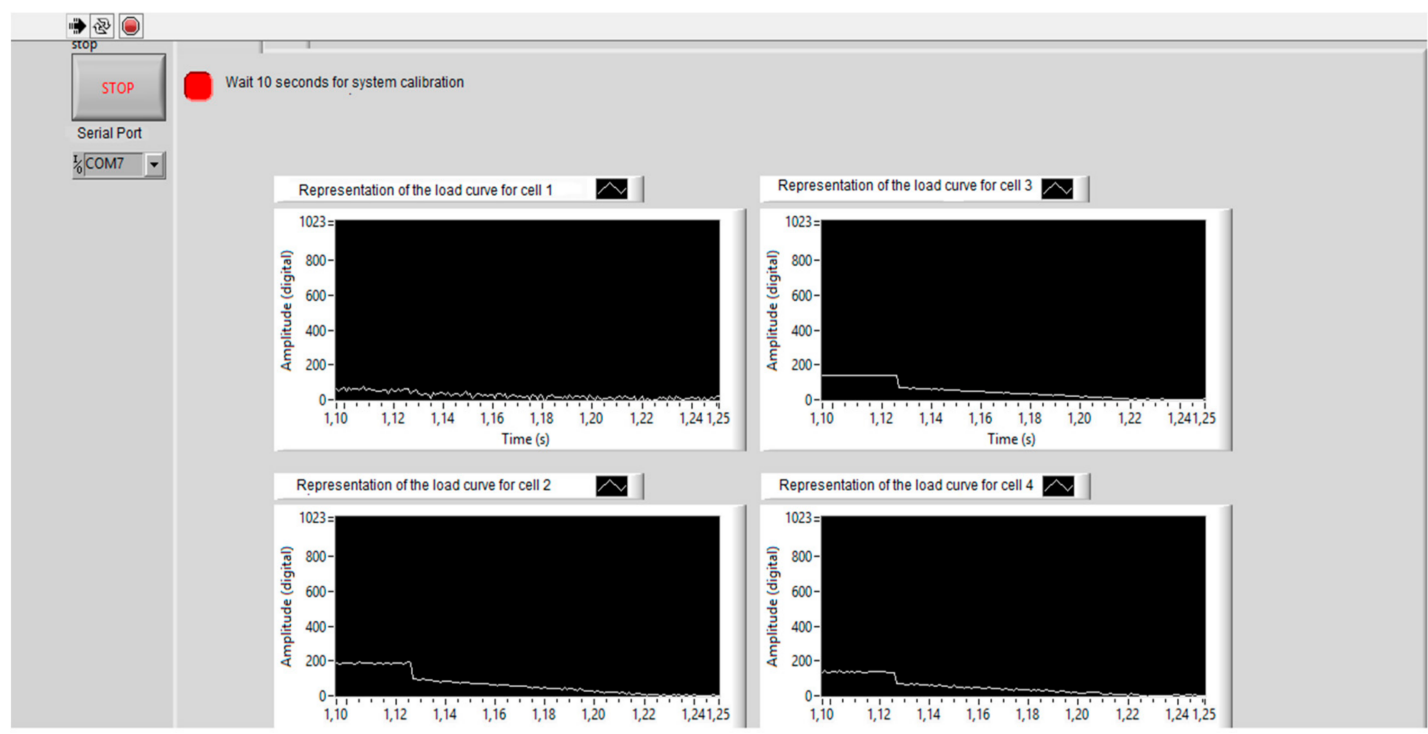

Figure 22. Calibration program interface.

All interfaces and functions of the platform for the user were built using LabView. The objective was to optimize and speed up the acquisition and treatment of the signals received by the platform, and to present them to the user in a straightforward manner and with self-describing functions.

\subsection{Force Platform}

The applied methodology allowed an adequate detailing of each of the processes adopted throughout the platform development project, from the design, specification of the material used, modeling and simulation of all parts, conditioning and acquisition circuit and, finally, the sampling method and interface. The final prototype (Figure 23) resulted in a very robust and widely functional force platform with a development cost of 100 USD (considering materials, machining, and electronic components).

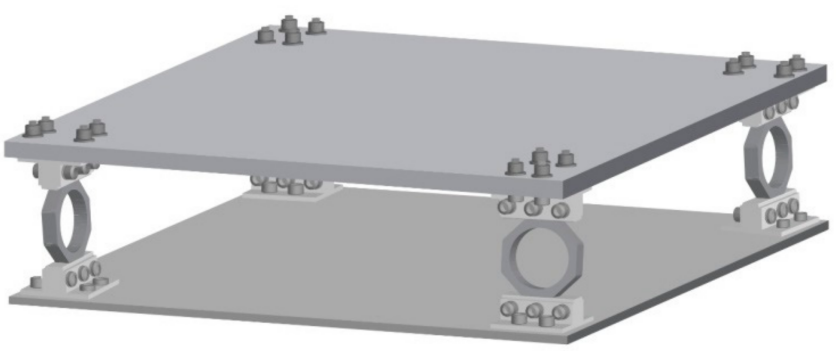

Figure 23. Final version of the force platform.

The 3D project for machining, simulation, development code for signal processing, platform calibration and data visualization (LabView) is available with free access and reproduction on the link https:/ / github.com/HelderGualberto/PI-VIII (accessed on 25 July 2021).

\section{Discussion}

- Load Cells and Extensometers 
A very common problem encountered in the use of strain gauges is the great influence of small variations in electrical resistance (in the milli ohms range). Due to the extremely high gain, these small resistance variations provide high levels of tension in the final amplification stage. Therefore, the imbalance of the bridge (variable with the length of the connecting wires, and even with the error in the resistances of the components) led to the construction of an offset adjustment on the bridge so that it is possible to balance the bridge from a trimpot. The major disadvantage of using this technique is the need to maintain the trimpot (TRIMPOT-1 in the circuit in Figure 14) without vibrations that alter its resistance and, consequently, unbalance the bridge. From the balanced bridge, the signal is sent to the first stage of amplification, with a gain equal to 100 times the input signal and, subsequently, to the second stage, there is a gain of 10 times. After the initial two stages, the signal undergoes a post-amplification offset adjustment, which is controlled by the TRIMPOT-2 shown in the circuit (Figure 14). This step will ensure control of the DC level of the output signal. This is very important to avoid saturation of the third amplification stage and to control the DC level for signal sampling, which will be dealt with later.

\section{- Sampling System}

Initially, the data package did not include any preamble, only the sequences of the most and least significant bytes referring to the load cell data. However, the loss of bytes was observed during the sending phase, which compromised the identification of the cells in the processing program (computer). Therefore, 4 bytes were added to identify the beginning and end of the packet, guaranteeing the sequence of its internal information. To perform serial communication between the microcontroller and the computer, an SDK called VISA (Virtual Instrument Software Architecture) was used in LabView. As the packets arrive, it is necessary to identify their order to ensure data synchrony and make corrections in case of packet loss.

A ring-shaped data structure was used to process the received data. This was necessary because LabView contexts work in an atomic way and even though the packages are coming out of order, there was no model implemented natively.

After the data sequences are validated, the information begins to pass through software filters. The first $10 \mathrm{~s}$ of the application consist of a calibration stage. This stage is performed to calculate an average of the signals received from the load cells so that it is possible to adjust the residual DC level in the data analysis steps.

\section{- User Interface (Data Normalization)}

Due to the high instability of the measuring circuits, it was necessary to develop dedicated circuits for each load cell. As a result, it was possible to minimize errors arising from ambient noise and sudden variations in the electrical resistance of the circuit components. However, due to the non-standardization of the circuits, signals with distinct gains were obtained for each load cell. Therefore, to ensure that the system interprets the signals with the same proportion, it was necessary to perform a calibration, using a known weight, and the characteristic equation of each cell.

- Application of the Force Platform in the Flight Analysis of Volleyball Athletes

The project was designed to meet two objectives. The first objective is to improve the sensitivity and reduce the costs of the existing platforms. In this way, it is possible to make a more detailed reading due to the improvement in sensitivity presented in the developed project of the platform, where it was possible to evidence that this objective was achieved. The second objective is to use the platform for analysis and characterization of flight time and postural characterization of volleyball athletes. This postural characterization was used only to validate the function of the designed instrument and the parameters and methods chosen in the design and manufacture of the platform [33].

Research directed to the development of equipment that allows a postural and strength assessment are extremely necessary not only for health professionals in the process of rehabilitation of patients with postural and strength analysis, as well as sports professionals 
and athletes who seek to improve their performance with decreased chance of injury. As a result, there is an increase in physical strength with biomechanical correction, corroborating the delay in muscle fatigue and stress [34,35].

Experiments on a larger population, such as a volleyball team, should be the subject of further research in which a study and sampling model that can be submitted to the ethics board is considered, allowing a more extensive analysis of the developed instrument. The expectation is that there will be integration with two instruments already developed as part of a parallel study, such as surface electromyography (EMG) [36] and a low-cost portable electrocardiogram (ECG).

The ECG developed by our group as part of a parallel project [37] is a mobile device that uses a standard 12-lead ECG at a sampling frequency of $250 \mathrm{~Hz}$ per lead. There is a connection via Bluetooth 4.0 used as a communication and data transfer interface. Furthermore, the EMG has typical operating frequencies ranging from $10 \mathrm{~Hz}$ to $1 \mathrm{kHz}$ (the EMG of our current prototype ranges between 3 and $50 \mathrm{~Hz}$ ), it is portable and easy to communicate [36]. In the future, the objective is to integrate both the ECG and EMG with the force platform, thus compose a kit of instruments that allow a complete and adequate study of the impacts of muscle degradation on different types of individuals, not just athletes.

\section{Conclusions}

Currently, there are several tools and instruments for evaluating the performance of athletes; however, they have many limitations, either regarding the operation or their high acquisition cost. For this reason, it is necessary to design new tools that can monitor and provide reliable data and that are sensitive to configuration changes during the performance of experiments.

In this project, an accurate and low-cost instrument was developed, accessible to healthcare professionals specializing in rehabilitation and, in particular, for use in research laboratories in biomechanics of the body and biomedical engineering. In this project, we focused mainly on load cells, from which all readings were extracted as a result of the deformation these cells undergo during operational use of the force platform. The geometry of the load cell design facilitates the use and arrangement of the extensometers, as well as the reading of the received and processed signals through amplification and conditioning circuit that, in a simple way, guarantees the reliable and adequate reading of both extensometers and load cells. Studies in the literature present some force platform projects and their use; however, the detailing of the platform manufacturing process is deficient and quite restricted to the use of commercial load cells, easily adapted to any platform. In addition, they have a high cost, which makes them often inaccessible.

In this project, the suggested force platform is made from low-cost, common and non-exclusive materials, as they can be purchased at any machining company and even at recycling centers. All modeling, simulation, circuits and source code projects were shared in detail throughout this work with the objective not only of facilitating reproduction, but also the customization and optimization of the instrument and its functions. The choice of LabView as the language for the development of signal processing and user interface software was due to the researchers' familiarity with the language and the possibility of generating an executable file that does not need a license for its use, thus ceasing to be a restricted character solution.

Finally, the importance of developing force platforms to assess balance and strength goes beyond their exclusive use in athletes or in different types of diseases associated with the elderly population. Nowadays, diseases resulting from poor posture and muscle strength degradation affect not only middle-aged people, but also the younger generation, due to back pain and other types of illnesses, where some problems may be related to working conditions or sedentary lifestyle. Symptoms associated with a specific disease can be identified by assessing body balance, strength, muscle strength or flexibility, which 
could lead to the developed platform, considered a tool for early diagnosis, and thus can help in preventing some diseases from becoming chronic.

Author Contributions: Conceptualization: J.R.B. and H.A.R.; methodology: J.R.B. and H.A.R.; software: H.A.R.; validation: J.R.B. and R.T.-S.; formal analysis: J.R.B.; investigation: H.A.R.; resources; data curation: J.R.B., H.A.R. and R.T.-S.; writing—original draft preparation: J.R.B.; writing—review and editing: J.R.B. and R.T.-S.; visualization: J.R.B., H.A.R., J.R., M.Z., E.S.-E. and R.T.-S.; project administration: J.R.B.; funding acquisition: J.R., M.Z. and E.S.-E. All authors have read and agreed to the published version of the manuscript.

Funding: This research received no external funding.

Acknowledgments: This research was supported by Universidad Nacional de San Agustín de Arequipa through research funding, the project "Think Health-Desarrollo de un kit de Instrumentos Biomédicos para centros de atención Básica de Salud y de auxilio al estudio de enfermedades crónicas y congénitas". Contract Nro. IBA-IB-44-2020-UNSA.

Conflicts of Interest: The authors declare no conflict of interest.

\section{References}

1. Barry, B.K.; Carson, R.G. The consequences of resistance training for movement control in older adults. J. Gerontol. Ser. A Boil. Sci. Med. Sci. 2004, 59, M730-M754. [CrossRef]

2. Pacheco, M.M.; Teixeira, L.A.C.; Franchini, E.; Takito, M.Y. functional vs. Strength training in adults: Specific needs define the best intervention. Int. J. Sports Phys. Ther. 2013, 8, 34-43.

3. Schaap, L.A.; Koster, A.; Visser, M. Adiposity, Muscle Masss, and Muscle Strength in Relation to Functional Decline in Older Persons. Epidemiol. Rev. 2013, 35, 51-65. [CrossRef]

4. Samadi, B.; Raison, M.; Detrembleur, C.; Ballaz, L. Real-time detection of reaction forces during gait on a ground equipped with a large force platform. In Proceedings of the 2014 Global Information Infrastructure and Networking Symposium (GIIS), Montreal, QC, Canada, 15-19 September 2014; pp. 1-3. [CrossRef]

5. Kutilek, P. Gait Evaluation in Patients with Transtibial Prosthesis using Force Platforms. In Proceedings of the 2018 18th International Conference on Mechatronics-Mechatronika (ME), Brno, Czech Republic, 5-7 December 2018; pp. 1-4.

6. Begg, R.; Rahman, S. A method for the reconstruction of ground reaction force-time characteristics during gait from force platform recordings of simultaneous foot falls. IEEE Trans. Biomed. Eng. 2000, 47, 547-551. [CrossRef] [PubMed]

7. Orsini, F.; Scorza, A.; D'Anna, C.; Pompeo, N.; Silva, E.; Sciuto, S.A.; Leccese, F. A Method For Force Platforms Dynamic Performances Characterization In Clinical Applications. In Proceedings of the 2018 IEEE International Symposium on Medical Measurements and Applications (MeMeA), Rome, Italy, 11-13 June 2018; pp. 1-6. [CrossRef]

8. Orsini, F.; Rossi, A.; Scorza, A.; Sciuto, S.A. Development and preliminary characterization of a novel system for the force platforms dynamic calibration. In Proceedings of the 2017 IEEE International Instrumentation and Measurement Technology Conference (I2MTC), Turin, Italy, 22-25 May 2017; pp. 1-6. [CrossRef]

9. Boukhenous, S.; Attari, M.; Remram, Y. Force platform for postural balance analysis. In Proceedings of the 2012 11th International Conference on Information Science, Signal Processing and their Applications (ISSPA), Montreal, QC, Canada, 2-5 July 2012; pp. 854-858. [CrossRef]

10. Ridwan, M.; Lan, M.F.; Fauzi, M.; Weeratunga, K. Development and validation of a force platform to measure ground reaction forces of national athletes. In Proceedings of the 2017 12th IEEE Conference on Industrial Electronics and Applications (ICIEA), Siem Reap, Cambodia, 18-20 June 2017; pp. 95-98. [CrossRef]

11. Ameen, M.J.; Hassan, A.A.; Al-Salakh, A.M.S.; Saadie, J.H.; Alnajem, A.M. Ring-Shaped Force Platform for Developing Instrumented Throwing and Shifting Forces Due to Rotation Analysis. In Proceedings of the 2020 IEEE International IOT, Electronics and Mechatronics Conference (IEMTRONICS), Vancouver, BC, Canada, 9-12 September 2020; pp. 1-5. [CrossRef]

12. Wang, H.; Liu, J.; Chen, S. An intelligent 3D force platform for plantar pressure distribution measurement. In Proceedings of the 2009 International Conference on Mechatronics and Automation, Changchun, China, 9-12 August 2009; pp. 4479-4483. [CrossRef]

13. Jian-Bo, Y.; Jia, R.; Yun-Fang, X. Global calibrating system design of three-dimensional force platform. In Proceedings of the 2017 29th Chinese Control and Decision Conference (CCDC), Chongqing, China, 28-30 May 2017; pp. 6037-6040. [CrossRef]

14. Hongguang, W.; Mingyang, Z.; Lijin, F.; Bo, Z.; Zhigang, X. Identification of Parameters for a Stewart Platform-based Force/Torque Sensor. In Proceedings of the 2004 IEEE International Conference on Robotics and Biomimetics, Shenyang, China, 22-26 August 2004; pp. 46-50. [CrossRef]

15. Silva, M.G.; Moreira, P.; Rocha, H.M. Development of a low cost force platform for biomechanical parameters analysis. Res. Biomed. Eng. 2017, 33, 259-268. [CrossRef] 
16. Tamburini, P.; Stagni, R.; Cappello, A. Design of a Modular Small Dimensions Force Platform for Gait Analysis. In 6th European Conference of the International Federation for Medical and Biological Engineering; Lacković, I., Vasic, D., Eds.; Springer: Cham, Switzerland, 2015; Volume 45. [CrossRef]

17. Rodríguez-Rubio, P.; Bagur-Calafat, C.; López-De-Celis, C.; Bueno-Gracía, E.; Cabanas-Valdés, R.; Herrera-Pedroviejo, E.; Girabent-Farrés, M. Validity and Reliability of the Satel $40 \mathrm{~Hz}$ Stabilometric Force Platform for Measuring Quiet Stance and Dynamic Standing Balance in Healthy Subjects. Int. J. Environ. Res. Public Health 2020, 17, 7733. [CrossRef] [PubMed]

18. Ernandes, R.D.C.; Brech, G.C.; Luna, N.M.S.; Nunes, M.F.; Greve, J.M.D.; Leme, L.E.G.; Alonso, A.C. Relationship of force platform with the clinical balance evaluation systems test in older adults. Acta Ortop. Bras. 2020, 28, 3. [CrossRef] [PubMed]

19. Neves, J.C.D.J.; Fernandes, K.B.P.; Fujisawa, D.S. What is the number attempts are necessary to evaluate postural control on a force platform in healthy children? J. Phys. Educ. 2019, 30, 1-7.

20. Madruga-Armada, Ó.; Becerro-De-Bengoa-Vallejo, R.; Losa-Iglesias, M.; Calvo-Lobo, C.; Rodriguez-Sanz, D.; Martínez-Jiménez, E.; Mazoteras-Pardo, V.; San-Antolín, M. Reliability and Repeatability of Pressure Center Analysis with Low-Dye Taping Using Force Platform Podiatry Sensors in Feet with Excessive Pronation. Int. J. Environ. Res. Public Health 2021, 18, 3265. [CrossRef]

21. Lueken, M.; Mueller, L.; Decker, M.G.; Bollheimer, C.; Leonhardt, S.; Ngo, C. Evaluation and Application of a Customizable Wireless Platform: A Body Sensor Network for Unobtrusive Gait Analysis in Everyday Life. Sensors 2020, 20, 7325. [CrossRef] [PubMed]

22. Ghirardelli, S.; Asay, J.; Leonardi, E.; Amoroso, T.; Andriacchi, T.; Indelli, P. Kinematic Comparison between Medially Congruent and Posterior-Stabilized Third-Generation TKA Designs. J. Funct. Morphol. Kinesiol. 2021, 6, 27. [CrossRef] [PubMed]

23. Konrad, A.; Reiner, M.; Bernsteiner, D.; Glashüttner, C.; Thaller, S.; Tilp, M. Joint Flexibility and Isometric Strength Parameters Are Not Relevant Determinants for Countermovement Jump Performance. Int. J. Environ. Res. Public Health 2021, 18, 2510. [CrossRef]

24. Arachchige, S.K.; Chander, H.; Turner, A.; Knight, A. Impact of Prolonged Exposure to a Slippery Surface on Postural Stability. Int. J. Environ. Res. Public Health 2021, 18, 2214. [CrossRef]

25. Cappello, A.; Bagalà, F.; Cedraro, A.; Chiari, L. Non-linear re-calibration of force platforms. Gait Posture 2011, 33, 724-726. [CrossRef]

26. Santos, B.R.; Delisle, A.; Larivière, C.; Plamondon, A.; Imbeau, D. Reliability of center of pressure summary measures of postural steadiness in healthy young adults. Gait Posture 2008, 27, 408-415. [CrossRef]

27. Russo, L.; D’Eramo, U.; Padulo, J.; Foti, C.; Schiffer, R.; Scoppa, F. Day-time effect on postural stability in young sportsmen. Muscle Ligaments Tendons J. 2015, 5, 38-42. [CrossRef]

28. Yanyan, Z.; Feng, G. Modal stimulation analysis for acoustic-structure coupling system of the aluminum alloy metro vehicle cavity. In Proceedings of the 2011 International Conference on Electric Information and Control Engineering, Wuhan, China, 15-17 April 2011; pp. 5951-5956. [CrossRef]

29. Bose, A.K.; Maddipatla, D.; Zhang, X.; Panahi, M.; Masihi, S.; Narakathu, B.B.; Bazuin, B.J.; Atashbar, M.Z. Screen Printed Silver/Carbon Composite Strain Gauge on a TPU Platform for Wearable Applications. In Proceedings of the 2020 IEEE International Conference on Flexible and Printable Sensors and Systems (FLEPS), Manchester, UK, 16-19 August 2020; pp. 1-5. [CrossRef]

30. Ghallab, Y.; Badawy, W. A new topology for a current-mode wheatstone bridge. IEEE Trans. Circuits Syst. II Express Briefs 2006, 53, 18-22. [CrossRef]

31. Jiang, H.; Ren, Y.; Zhang, S.; Liu, Z.; Yu, G.; Xiang, J. Damage and perforation resistance behaviors induced by projectile impact load on bonding-patch repaired and scarf-patch repaired composite laminates. Int. J. Damage Mech. 2018, 28, 502-537. [CrossRef]

32. Xu, Y.-X.; Juang, J.-Y. Measurement of Nonlinear Poisson's Ratio of Thermoplastic Polyurethanes under Cyclic Softening Using 2D Digital Image Correlation. Polymer 2021, 13, 1498. [CrossRef] [PubMed]

33. Faries, M.D.; Greenwood, M. Basic training: Stabilizing the confusion. Strength Cond. J. 2007, 29, 10-25. [CrossRef]

34. Zemková, E. Instability resistance training for health and performance. J. Tradit. Complement. Med. 2017, 7, 245-250. [CrossRef] [PubMed]

35. Zemková, E.; Hamar, D. Sport-Specific Assessment of the Effectiveness of Neuromuscular Training in Young Athletes. Front. Physiol. 2018, 9, 264. [CrossRef] [PubMed]

36. Singh, A.; Calixto, G.M.; Felisbino, C.H.D.; Zuffo, M.K.; Garay, J.R.B. EMG instrumentation for educational physiotherapy research. In Proceedings of the 2016 IEEE International Symposium on Consumer Electronics (ISCE), Sao Paulo, Brazil, 28-30 September 2016; pp. 101-102. [CrossRef]

37. Huamani, R.; Talavera, J.R.; Mendoza, E.A.S.; Davila, N.M.; Supo, E. Implementation of a real-time $60 \mathrm{~Hz}$ interference cancellation algorithm for ECG signals based on ARM cortex M4 and ADS1298. In Proceedings of the 2017 IEEE XXIV International Conference on Electronics, Electrical Engineering and Computing (INTERCON), Cusco, Peru, 15-18 August 2017; pp. 1-4. [CrossRef] 